\title{
A study on cercarial dermatitis in Khuzestan province, south western Iran
}

\author{
Ali Farahnak*1 and Mostafa Essalat ${ }^{2}$
}

\begin{abstract}
Address: ${ }^{1}$ Department of Parasitology and Mycology, School of Public Health, Tehran University of Medical Sciences, Tehran, 6446-14155, Tehran, Iran and 2 Department of Pathology, School of Medicine, Tehran University of Medical Sciences, Tehran, Iran

Email: Ali Farahnak* - farahnak@sina.tums.ac.ir; Mostafa Essalat - essalatsm@sina.tums.ac.ir

* Corresponding author
\end{abstract}

Published: 07 November 2003

BMC Public Health 2003, 3:35

This article is available from: http://www.biomedcentral.com/I47I-2458/3/35

(C) 2003 Farahnak and Essalat; licensee BioMed Central Ltd. This is an Open Access article: verbatim copying and redistribution of this article are permitted in all media for any purpose, provided this notice is preserved along with the article's original URL.
Received: 0 I July 2003

Accepted: 07 November 2003

\begin{abstract}
Background: Cercarial dermatitis' or swimmer's itch' is an itchy inflammatory response to the penetration of the skin by non-human schistosome parasites. In the hot season, (May to September) in Khuzestan province in the south west of Iran, swimming in canals and agriculture activities in swampy areas are common. This survey was made on people from villages north of Ahwaz city in south west Iran, to estimate cercarial dermatitis in this region.
\end{abstract}

Methods: 2000 people were observed for clinical signs of cercarial dermatitis. Also 2000 Lymnaea gedrosiana snails were collected from agriculture canals and examined for animal schistosome cercariae during 1998-2000.

Results: From this survey I.I\% of people had pruritic maculopapular rash on their feet, hands or other parts of body. From the total of examined snails, $2.4 \%$ were found to be infected with bird schistosome cercariae including Trichobilharzia species.

Conclusion: Cercarial dermatitis could be a health problem in this area. This is the first report of cercarial dermatitis from this region of Iran.

\section{Background}

Cercarial dermatitis is a parasitic disease that has worldwide distribution. Dermatitis caused by the cercariae of animal shistosomes has been reported from many countries in Europe and America [1-6]. Furthermore, an examination of Lymnaea stagnalis snails in Germany showed a constant low prevalence of Trichobilharzia cercariae [7].

Khuzestan province in the south west of Iran, has very hot $\left(>50^{\circ} \mathrm{C}\right)$ weather from May to September. The people of this area swim in the rivers and agriculture canals during summer to reduce their body temperature. At the same time various fresh water snails, including Lymnaea gedrosiana are observed to be abundant in the these canals. In this respect, the author observed many snails in agriculture canals in this region during a previous research project entitled "Faunistic survey on cercariae of fresh water snails"[8]. It must be mentioned, the domestic and wild ducks are common in this region.

The purpose of the present study was to determine the animal schistosome cercariae in Lymnaea snails and human cercarial dermatitis in this rural area of south western Iran. 


\section{Methods}

The rural area to the north of Ahwaz city including, Bamdezh and Mazreeh districts were chosen for this study, because there are many canals in this region.

\section{Cercarial dermatitis detection}

To detect human case(s) of cercarial dermatitis, During 1998-2000 the field team visited the 2000 people in a home to home intervention and asked for the presence of itching and maculopapular rash or eruption on the body especially hands or feet during 1998-2000. Clinical symptoms were recorded. This study was approved by Ethic Committee of Tehran University of Medical sciences.

\section{Cercariae detection from Lymnaea gedrosiana}

To detect snails infected with animal schistosome cercariae, 2000 Lymnaea gedrosiana snails were collected and transferred to Ahwaz health research centre. To obtain cercariae, Lymnaea snails were examined for shedding cercariae by using artificial light or leaving over night or by crushing methods by removing the snails and crushing them against a glass plate. Cercariae were collected and fixed in 5\% hot formaldehyde and cleared in lactophenol or stained with azocarmine. Cercariae were identified by systematic key references [9].

\section{Results}

From the people examined in this survey for cercarial dermatitis 22 persons $(1.1 \%)$ were found to have dermatitis symptoms. Dermatitis was observed as a macular or papular rash on the hands or feet. The symptoms were abundant in children (figure 1). These symptoms appeared on the author's hand after handling infected snails in the laboratory.

From the total of Lymnaea snails which were examined for animal schistosome cercariae, $48(2.1 \%)$ were found to be infected with brevifurcate-apharyngeate distome cercariae, Trichobilharzia sp. (Figure 2).

\section{Discussion}

Trichobilharzia spp cause cercarial dermatitis as a result of their penetration into the skin [10]. There are no readily available and easy tests for cercarial dermatitis. Diagnosis is based on a history of exposure to water that may be contaminated with cercariae. Cercarial dermatitis has been reported from Caspian Sea region in the north of Iran [11]. In the summer season, Khuzestan province in the south west of Iran is very hot. For this reason, people especially children swim and play in the rivers or canals which are used for agriculture purposes. In addition many young children work on the agricultural farms without any protection on their hands or feet areas where animal schistosome cercariae can readily penetrate the skin. The
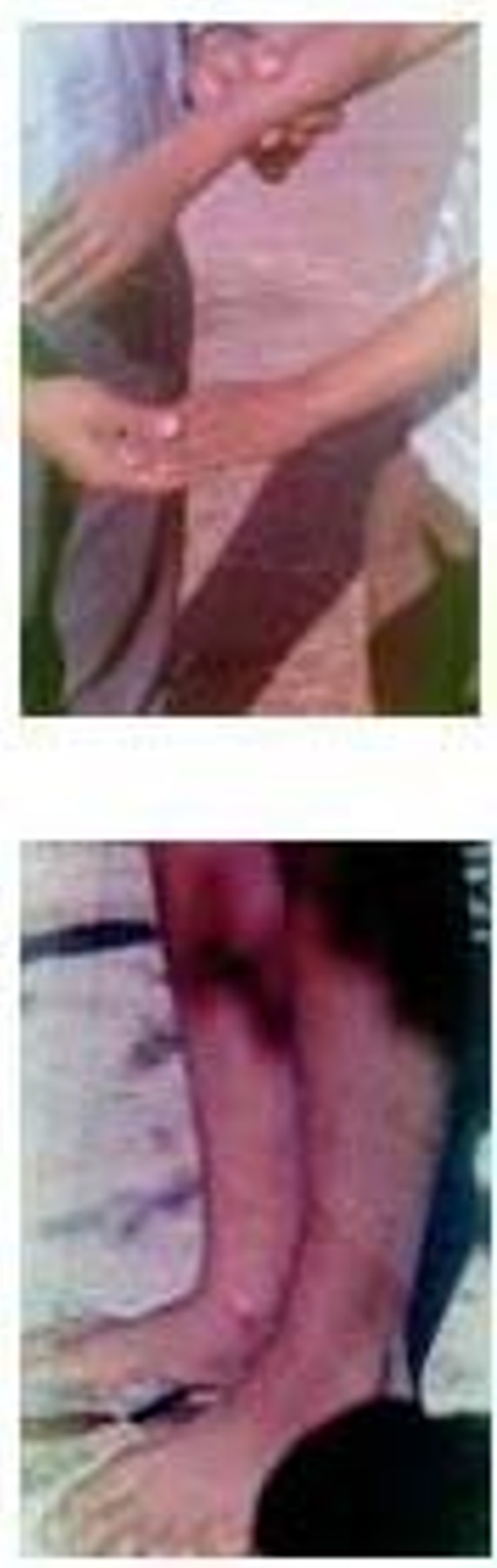

Figure I

Maculopapular rash on hands and feet in cercarial dermatitis. 

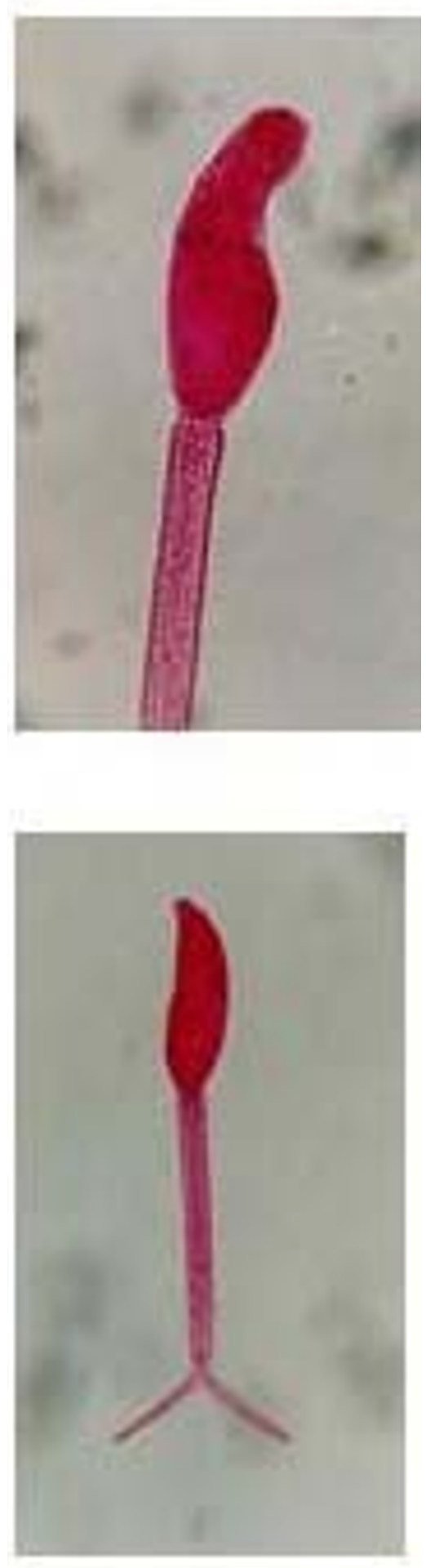

\section{Figure 2}

Cercaria of Trichobilharzia species majority of cercarial dermatitis cases were observed as maculopapular rashes in the children. According to their claims, a burning sensation appeared after water drops had dried on their skin and they had itchy sensation on the skin. Symptoms started with erythema (reddening of the skin), itching and several hours later maculopapular rashes appeared. Most frequently cases occur in July to August due to shedding cercariae and people bathing. The people use saline water for the treatment of itching and dermatitis. Although, they claimed, their itching had reduced by saline water; however these patients were referred to physicians for treatment with cortisone cream. Cortisone (steroid) skin preparations decreased local swelling and itching. People were satisatified by the reducing itching or disappearance of rashes. Minutes after handling cercariae infested water, the author experienced a prickling sensation or itchiness on his hand, after several hours erythema and urticaria developed.

Lymnea gedrosiana snails are abundant in the canals and living in different ecological habitats. They were observed at the oxygenated marginal water surface of canals. Various cercariae species including, xiphidiocercariae, strigeid cercariae, echinostome cercariae, and animal schistosome cercariae were obtained from Lymnaea gedrosiana in the health research laboratory by shedding or crushing methods. Cercariae of animal schistosomes could be confused with strigeid cercariae, however, the former lack a pharynx. These cercariae belonged to non-human schistosome especially bird schistosomes including, Trichobilharzia spp. This bird schistosome was, with its total body length of approx. 700-800 $\mu \mathrm{m}$, large and was easy to distinguish with the naked eye. Good features for recognition were the bifurcated tail, eyespots, flame cells and arrangement of penetration glands [4]. Two eyespots were found in the body; the pharynx and oral sucker were fused together into a head organ; the intestinal system was reduced. The cercariae were strongly positively phototactic, i.e. they swimed towards a light source and congregated there.

The simultaneous occurrence of three phenomena, bathing habits, colonization by Lymnaea, and settlement of many duck colonies combined with long hours of sunshine in the summer, are responsible for most of the foci of cercarial dermatitis. Control of this condition is difficult, requiring strict maintenance of bodies of water and if necessary the use of molluscicides such as niclosamide. The use of praziquantel in baits for treating the definitive hosts appears to interrupt the natural cycle of avian schistosomatidae [12].

\section{Conclusions}

In brief, due to presence of infected snails and bathing of swimmers, cercarial dermatitis in the Khuzestan people especially children is noted in the hot summer season. 


\section{Competing interests}

None declared.

\section{Authors' contributions}

AF: Parasitologist and Principle investigator

\section{ME: Pathologist}

\section{Acknowledgements}

This study was supported by a grant from Tehran University of Medical Sciences. The Authors would like to thank the staff of Ahwaz Health Research Centre for their field assistants especially, M. Saffar for managing field work, M. Foladvand, A. Siavashpouri, F. Kasiri for collection of snails. Thanks also to physicians of Ahwaz Health Care Centers for treatment of patients.

\section{References}

I. De Gentile L, Picot H, Bourdeau P, Bardet R, Kerjan A, Piriou M, Le Guennic A, Bayssade-Dufour C, Chabasse D, Mott KE: Cercarial dermatitis in Europe: a new public health problem? Bull World Health Organ 1996, 74:159-63.

2. Bastert J, Sing A, Wollenberg A, Korting HC: Aquarium dermatitis: cercarial dermatitis in an aquarist. Dermatology 1998, 197:84-6.

3. Folster-Holst R, Disko R, Rowert J, Bockeler W, Kreiselmaier I, Christophers E: Cercarial dermatitis contracted via contact with an aquarium: case report and review. $\mathrm{Br}$ J Dermatol 200I, 145:638-40.

4. Kolarova L, Skirnisson K, Horak P: Schistosome cercariae as the causative agent of swimmer's itch in Iceland. J Helminthol 1999 , 73:215-20.

5. Chamot E, Toscani L, Rougemont A: Public health importance and risk factors for cercarial dermatitis associated with swimming in Lake Leman at Geneva, Switzerland (abstract). Epidemiology Infect 1998, I 20:305- I4.

6. Lindblade KA: The epidemiology of cercarial dermatitis and its association with limnological characteristics of a northern Michigan lake. J Parasitol 1998, 84:19-23.

7. Loy C, Haas W: Prevalence of cercariae from Lymnaea stagnalis snails in a pond system in Southern Germaney. Parasitol Res 200I, 87:878-82.

8. Farahnak A, Massoud J: Study on Cercariae (Trematodes Larvae) of Heterophyidae in Melanopsis and Melanoides (Freshwater Snails). J of Shahid Beheshti University 200I, 25:257-262.

9. Frandsen F, Christensen NO: An introductory guide to the identification of cercariae from African freshwater snails with special reference to cercariae of trematode species of medical and veterinary importance. Acta Trop 1984, 41: |8|-202.

10. Horak P, Kolarova L: Bird schistosomes - do they die in mammalian skin? Trends in Parasitology 2001, 1 7:66-69.

II. Sahba GH, Malek EA: Dermatitis caused by cercariae of Orientobilharzia turkestanicum in the Caspian Sea area of Iran. Am J Trop Med Hyg 1979, 28:912-3.

12. Blankespoor CL, Reimink RL, Blankespoort HD.: Efficacy of praziquantel in treating natural schistosome infections in common mergansers. J Parasitol 2001, 87:424-6.

\section{Pre-publication history}

The pre-publication history for this paper can be accessed here:

http://www.biomedcentral.com/1471-2458/3/35/prepub

Publish with Biomed Central and every scientist can read your work free of charge

"BioMed Central will be the most significant development for disseminating the results of biomedical research in our lifetime. "

Sir Paul Nurse, Cancer Research UK

Your research papers will be:

- available free of charge to the entire biomedical community

- peer reviewed and published immediately upon acceptance

- cited in PubMed and archived on PubMed Central

- yours - you keep the copyright

Submit your manuscript here:

http://www.biomedcentral.com/info/publishing_adv.asp
BiolMedcentral 